\title{
Clinical experiences with cartilage repair techniques: outcomes, indications, contraindications and rehabilitation
}

\author{
Kıkırdak tamir teknikleri ile klinik deneyimler: \\ Sonuçlar, endikasyonlar, kontrendikasyonlar ve rehabilitasyon
}

\author{
Ágnes Berta, MD., Zsófia Duska, MD., Ferenc Tóth, MD., László Hangody, MD. \\ Department of Orthopedics and Traumatology, Uzsoki Hospital, Budapest, Hungary
}

\begin{abstract}
Untreated articular cartilage defects may lead to chronic joint degeneration and functional disability. In the past decade, several cartilage repair techniques have emerged for the treatment of cartilage lesions. Among these techniques, mosaicplasty was introduced by the senior author into the clinical practice in 1992. This article does not intend to give a review or a comparison of currently existing surgical techniques which aim to repair symptomatic focal defects; however, it focuses on the procedures used in the everyday practice in the authors' institute, namely microfracture, mosaicplasty, autologous chondrocyte implantation (ACI), osteochondral allograft transplantation and biodegradable osteochondral scaffolds. It gives a brief summary of these well-described techniques, summarizes the authors' clinical experience and available data on the clinical outcome, and the rehabilitation protocol following different procedures, with a special emphasis on mosaicplasty.

Keywords: Autologous chondrocyte implantation; biodegradable scaffolds; cartilage repair techniques; microfracture; mosaicplasty; osteochondral allograft transplantation.
\end{abstract}

öz

Tedavi edilmemiş eklem kıkırdak defektleri, kronik eklem dejenerasyonuna ve fonksiyonel engelliliğe neden olabilir. Son 10 yılda kıkırdak lezyonlarının tedavisinde çeşitli kıkırdak tamir teknikleri geliştirilmiştir. Bu tekniklerden mozaikplasti, 1992 yılında kıdemli bir yazar tarafından klinik uygulamaya taşınmıştır. Bu makalede günümüzde semptomatik fokal defektlerin tamirinde kullanılan mevcut cerrahi tekniklere ilişkin bir derleme veya karşılaştırma yapılmadı; ancak yazarların çalıştı̆̆ yaşamda kullandıkları mikrokırık, mozaikplasti, otolog kondrosit implantasyonu (OKI), osteokondral allogreft transplantasyonu ve biyolojik olarak bozunabilir osteokondral iskelet işlemleri irdelendi. $\mathrm{Bu}$ yazı iyi tanımlanan tekniklerin kısa bir özeti niteliğinde olup, mozaikplasti bağlamında yazarların klinik deneyimini ve klinik sonuca ilişkin mevcut verileri ve farklı işlemlerin rehabilitasyon protokollerini özetlemektedir.

Anahtar sözcükler: Otolog kondrosit implantasyonu; biyobozunur iskeletler; kıkırdak onarım teknikleri; mikrokırık; mozaikplasti; osteokondral allogreft transplantasyonu.
As human adult cartilage has a very low intrinsic activity and limited capacity for self-repair, spontaneous healing of chondral and osteochondral defects cannot be expected. Cartilage defects may cause pain and disability; therefore, early biological reconstruction of the joint should be attempted to avoid progression of the condition to osteoarthritis. Although our knowledge on hyaline cartilage morphology, its physiological and pathological characteristics has been increasing, actual reproduction of hyaline cartilage cannot be achieved, yet. Current cartilage repair techniques are only the best possible options according to our current level of knowledge; however, they have proved to provide effective pain relief and restoration of joint function.

The process of cartilage repair should start with clarification of the underlying cause, and if it is still present (instability, abnormal pressure 
conditions caused by malalignment, structural anomalies, etc.), it should also be treated. Therefore, surgical treatment usually has two components: correction of biomechanical alterations (ligament reconstruction, corrective osteotomy, menisectomy or suture/replacement of the torn meniscus, etc.) and restoration of the cartilage surface. Treatment of additional joint abnormalities should be incorporated in the operative and postoperative rehabilitation algorithms; otherwise, early wear of the resurfaced area or even more progressed degeneration may develop.

The success rate of a cartilage repair procedure equally depends on choosing a appropriate technique and proper rehabilitation protocol for the patient. Rehabilitation should support both cartilage repair and concomitant procedures; furthermore, requirements of rehabilitation may determine possible combinations of techniques and timing of procedures.

In this review article, we focus on techniques currently used in the authors' institute to repair defects of knee joint cartilage: microfracture, mosaicplasty, autologous chondrocyte implantation (ACI), osteochondral allograft transplantation and biodegradable osteochondral scaffolds. We aim to present the authors' clinical experiences with varying cartilage repair procedures as well in the light of clinical outcomes and the recommended rehabilitation protocol.

\section{CARTILAGE REPAIR TECHNIQUES}

\section{Marrow stimulation techniques}

Marrow stimulation techniques utilize the spontaneous healing process of musculoskeletal tissue. Penetration of the subchondral plate underneath the lesion promotes bleeding and formation of a clot over the defected area. Localized inflammatory response in the clot stimulates proliferation of bone marrow derived mesenchymal stem cells with chondrogenic potential and the ability to create a repair tissue.

Microfracture was introduced by Steadman et al..$^{[1]}$ and has gradually gained popularity over transcortical Pridie drilling and abrasion arthroplasty, becoming the most widely used bone marrow stimulation technique. After creating a healthy vertical cartilage margin to the lesion, the calcified cartilage layer is removed with the help of a curette and, then, the subchondral plate is perforated with an arthroscopic awl to allow bleeding and clot formation over the defect.
Microfracture has the advantage over Pridie drilling that heat generation -which may affect the viability of the bone and bone marrow, compromising tissue repair-caused by drilling can be avoided and the angled awl allows perforation of the subchondral plate on places, otherwise, inaccessible for perpendicular drilling. During abrasion arthroplasty, the superficial layer of the subchondral bone is removed using an arthroscopic burr to create indentations on the base of the defect, which facilitates bleeding. The technique has the risk of excessive abrasion, leading to undesirable changes in the contour of the articular surface, and consequently to incongruency, which can be also eliminated by choosing microfracture for cartilage repair.

Microfracture is simple to perform, can be done arthroscopically, and is a relatively inexpensive procedure. The newly formed tissue, however, consists of fibrocartilage, and is less resistant to wear and compressive forces than hyaline cartilage. Microfracture provides immediate relief of symptoms caused by the lesion in most cases; however, the results are often unpredictable. The technique can be improved by placing a biodegradable, cell-free membrane over the area of microfracture (autologous matrix induced chondrogenesis) in a one-stage procedure. The membrane retains bone marrow derived pluripotent mesenchymal cells over the defect and provides a protected environment for cartilage regeneration. ${ }^{[2]}$

Although there is no comprehensive follow-up study conducted on the outcome of microfracture in the authors' institute, the improvement and failure rates correspond with that of described in other institutes.

\section{Mosaicplasty}

Mosaicplasty allows resurfacing chondral and osteochondral lesions by harvesting and transplanting cylindrical osteochondral plugs from less weight-bearing peripheral patellofemoral area and inserting them into drilled tunnels in the defective section of the cartilage. Graft implantation in a mosaic-like fashion offers an effective management of small and medium-sized focal defects, and based on clinical practice, the majority of focal defects are within this category. Mosaicplasty also ensures good results in most cases and the findings of control arthroscopies and histological evaluations attest to the clinical observations.

The main disadvantage of autologous osteochondral transplantation is limited availability 
of donor area. Further disadvantage may be potential morbidity of the donor area caused by harvesting osteochondral grafts from a previously intact cartilage surface. Several long-term followup studies have shown that donor site morbidity occurs in about $3 \%$ of the cases, ${ }^{[3]}$ provided the recommended indications and technical details are taken into account (grafts $8.5 \mathrm{~mm}$ or less in diameter; avoiding extreme extent in graft removal, using the recommended low weight-bearing areas).

The first ever mosaicplasty was performed in the authors' institution at February $6^{\text {th }}, 1992$. Long-term surgical outcomes of 354 professional athlete patients were reported, who had knee or talar mosaicplasty in 303 and 39 cases, respectively, between 1992 and 2008 in a multicenter prospective follow up study. ${ }^{[3]}$ The mean follow-up period was 9.6 years, ranging from 2 to 17 years. The patients were evaluated at six weeks, three months, six months, and annually afterwards by modified Hospital for Special Surgery (HSS), Lysholm, modified Cincinnati, and International Cartilage Repair Society (ICRS) scores following knee mosaicplasty and by Hannover ankle score following talar mosaicplasty. Magnetic resonance imaging was performed before surgery, at six months and one year postoperatively, while standard X-rays were done preoperatively, at six weeks and six months, and annually afterwards. Possible donor site and femoropatellar complaints were assessed by the Bandi scoring system. Second-look arthroscopies were required in 21 cases due to persistent or recurrent pain, swelling, postoperative synovitis or a new injury, whereas 11 patients gave a consent for biopsy harvesting from the resurfaced area.

Clinical scores showed good to excellent results in $91 \%$ of femoral condylar, $86 \%$ of tibial condylar, $74 \%$ of patellotrochlear, and $92 \%$ of talar mosaicplasties. Donor site complaints were found in $5 \%$ of the cases.

Good, congruent, and gliding surfaces were obtained during second-look arthroscopies on the recipient sites and acceptable fibrocartilage covering of donor sites in 16 cases, although, five patients had moderate to severe degenerative changes on the recipient sites. Histological examination of the samples taken from the recipient site showed good graft incorporation in all 11 cases, type II-specific normal articular cartilage collagen, and articular cartilage proteoglycans in most cases, while severe degeneration was found in three cases.

Returning to sports activity was also identified as an important factor in the postoperative evaluation of competitive athletes. A total of $63 \%$ of the patients returned to the same level of sports activity, and five out of them participated in four Olympic Games. A total of $28 \%$ of the patients were able to return to a lower level of sports activity following surgery, while 9\% of them choose to stop any kind of sports activity. In summary, mosaicplasty proved to be a successful alternative in the treatment of focal chondral and osteochondral lesions in the high-demand group of competitive athletes.

\section{Osteochondral allograft transplantation}

For the treatment of extended osteochondral defects, limited availability of donor area necessitated the reconsideration of osteochondral allograft transplantation, the historically first cartilage repair technique; Lexer published transplantation of whole or half joints derived from freshly amputated extremities in 1908. ${ }^{[4]}$ Although the first attempts of transplanting ostechondral functional units as allografts were less successful due to lack of proper tissue typing and detailed infectological background, the technique gained popularity again in the $1970 s,{ }^{[5,6]}$ and became a wellestablished technique for the treatment of massive cartilage defects.

It has been shown that transplanted chondrocytes are capable of surviving in the host environment, and that graft bone can be completely replaced by host bone via creeping substitution. ${ }^{[7]}$ Viability of chondrocytes is the most critical factor for good clinical outcomes of osteochondral allograft transplantation, as they maintain the extracellular matrix, and, thereby, the function of cartilage tissue over time. In cryopreserved cartilage, cell survival rate has been shown to be quite poor, about $20-30 \%,{ }^{[8]}$ and even though fresh, refrigerated cartilage retains higher viability, prolonged storage of fresh human osteochondral allograft tissue for more than 14 days has been demonstrated to lead to significant decreases in chondrocyte viability, viable cell density, and metabolic activity. ${ }^{[0]}$

To ensure adequate chondrocyte survival rate, we aim to minimize the time-span between graft harvest from cadavers and transplantation for less, than 12-24 hours in our institution. Furthermore, we introduced living donor transplantation into our practice, when grafts were harvested from patients scheduled for total hip or knee replacement surgeries, and gave a consent to donate osteochondral blocks removed during the procedure (namely the caudal part of the femoral head or the lateral femoral condyle in case of varus deformity). The donors were 
selected based on preoperative radiological images and macroscopic appearance of the cartilage during surgery. The harvested osteochondral blocks were stored in physiological saline solution, while the recipient area was prepared and were cut to match the size and shape of the lesion following debridement. The allograft was, then, fixed to the recipient site by osteosynthesis, e.g. plates and screws (Figure 1). In addition to the shorter time-frame between graft harvest and transplantation, further advantage of living donor transplantation is that patients are scheduled for total joint replacements well in advance, allowing sufficient time for preoperative planning and virus screening to avoid the risk of viral transmission. Moreover, the technique permits osteochondral allograft transplantation in centers without an access to tissue banks.

Prior to the first living donor transplantation, histological examination was conducted to establish that cartilage surfaces of structural osteochondral grafts which were considered macroscopically intact by the surgeon were eligible for transplantation. ${ }^{[10]}$ Altogether 27 osteochondral samples were examined, 15 were identified as suitable for transplantation by the surgeon. Twelve had a visibly deteriorated cartilage surface. The potentially suitable grafts were categorized histologically as good or acceptable in 14 cases and as unacceptable for transplantation in one case, while the samples with a visibly degenerated cartilage surface were found to be histologically damaged. It must be noted that, even though it is possible to harvest histologically acceptable grafts during total joint replacement procedures, cartilage surfaces of the donor joints are destroyed by a degenerative process; therefore, the proportion of the osteochondral blocks which are suitable for transplantation is always smaller in size than that of the grafts obtained from intact cadaveric joints.

The common complication of graft-versus-host disease following allogenic tissue transplantation
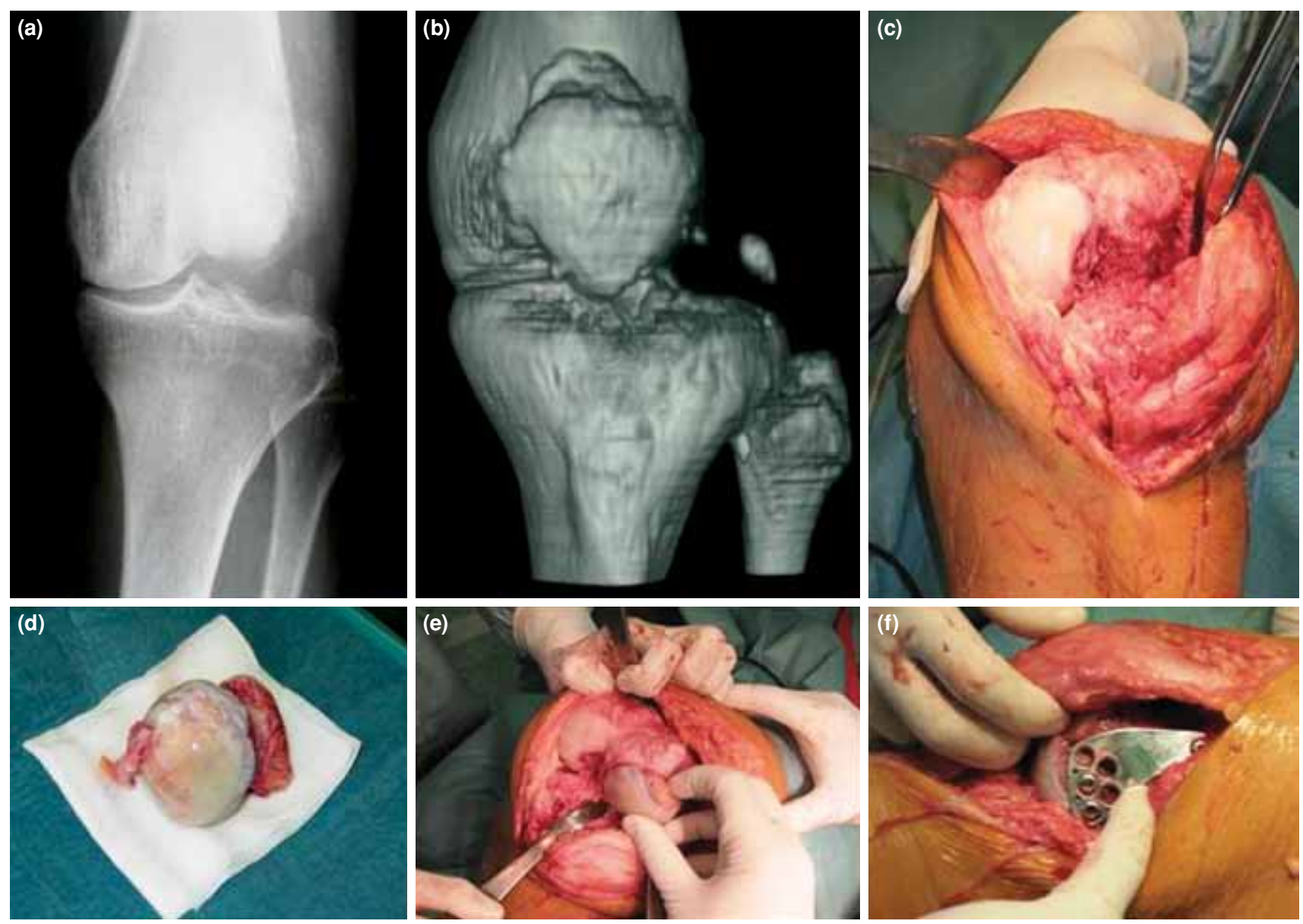

Figure 1. (a) Preoperative X-ray and (b) computed tomography of a massive osteochondral defect (c) caused by a septic complication following internal fixation of a lateral femur condyle fracture, (d) graft harvested from a living donor, (e) insertion of the graft trimmed to the shape of the defect, (f) fixation of the graft. 
can be avoided by thorough jet lavage irrigation of the donor cancellous bone to remove cellular components. Chondrocytes are tightly embedded in the extracellular matrix, thus, not exposed to the recipient immune system, which obviate the need for immunosuppressive therapy along with meticulous irrigation of the bone.

\section{Autologous chondrocyte implantation}

Since limitations and potential complications of allografting and autografting prompted the development of autologous chondrocyte implantation, the concept published by Brittberg ${ }^{[11]}$ in 1994 added a novel revolutionary dimension to musculoskeletal surgery and cell therapy became a practical possibility.

Autologous chondrocyte implantation is a twostage procedure. Firstly, an arthroscopy is performed to evaluate the size and depth of the lesion and to harvest cartilage biopsy from the superomedial or superolateral edge of the femoral condyle or the lateral intercondylar notch. Chondrocytes are, then, isolated by enzymatic degradation of the extracellular matrix from the biopsy sample and cultured in vitro to expand the chondrocyte population. Secondly, the lesion is exposed via a mini-arthrotomy and debrided and, then, a periosteal flap is obtained from the proximal medial tibia and sutured to the defect margins with the cambium layer facing down to provide a watertight seal for the cell suspension injected underneath it. Following chondrocyte implantation, the knee should not be placed through its range of motion (ROM); any concomitant procedures, therefore, should be performed before resurfacing of the lesion.

Excellent long-term clinical and functional outcomes of ACI prove the effectiveness and durability of the method. In a clinical study including 224 patients during a mean follow-up period of 13 years (range, 10 to 20 years) following ACI, Peterson et al. ${ }^{[12]}$ reported good-to-excellent clinical improvement from baseline in Lysholm, Tegner and Brittberg-Peterson scores and 92\% of patients (202 of 219) were satisfied and would have the surgery again.

On the other hand, using a periosteal flap to cover the cultured chondrocytes as described in the original method of $\mathrm{ACI}$, it can lead to certain complications: hypertrophy of the graft, calcification and delamination have been reported. ${ }^{[13]}$ Together with extensive surgical exposure and longer operating time required for periosteum harvest, these complications facilitated the improvement of the technique; creating a flap from biodegradable materials obviating the need to remove the tibial periosteum.

In a prospective, randomized study comparing the clinical outcome of 33 ACI procedures using periosteal cover and 35 cases using type I/III collagen membrane flap, Gooding et al. ${ }^{[14]}$ showed that there is no statistical difference between the two techniques. Patients were followed for two years and $74 \%$ of the patients who received collagen membrane and $67 \%$ of the patients who had periosteal flap as a cover for retaining chondrocytes had good or excellent clinical and functional results. Second-look arthroscopies and evaluation by the ICRS grading system at one year also showed similar results for both techniques. However, a significant number $(36.4 \%)$ of patients required additional surgery and shaving due to graft hypertrophy in the periosteum group, while none of the patients in the collagen membrane group suffered from this complication.

Injection of expanded chondrocyte suspension underneath a membrane raised concerns about the potential to an uneven distribution of the cells in the defect and to cell leakage, leading to further improvement of the ACI technique. Biodegradable scaffolds have been developed for a more reliable and simplified method to cell delivery into the cartilage lesions. The cultured chondrocytes are seeded onto the biodegradable scaffolds prior to implantation, which are, then, shaped to match the contours of the lesion and fixed onto it (matrix-induced autologous chondrocyte implantation, MACI technique). ${ }^{[13]}$

Currently, numerous carrier materials are available. In the senior author's practice, mainly a hyaluronic acid-based three dimensional scaffold, Hyalograft-C is used for the delivery of chondrocytes, while scaffolds of Genzyme and IsoTis are also used. The method is not widely adopted due to high laboratory costs and the fact that it is not covered by the national health insurance system. Experiences indicate that this modified method has a technical advantage, as mechanical properties of the graft allow secure fixation with sutures and fibrin glue from a less extensive surgical approach, which is of particular benefit when cartilage repair is combined with other procedures such as high tibial osteotomy or ligament reconstruction. The authors' early results are encouraging; however, further clinical evidences and histological evaluations are required to validate the long-term outcomes. The findings of second-look arthroscopies- which were performed in five cases at 12 to 18 months following MACI-showed that the resurfaced area was well-covered with a continuous, 
but soft reparative tissue (Figure 2). Elasticity of the newly formed tissue was decreased compared to the stiffness of normal hyaline cartilage; however, patients were symptom-free and satisfied with the outcome of the surgery.

\section{Biodegradable osteochondral scaffolds}

Application of cylindrical, biodegradable scaffolds for the treatment of focal chondral and osteochondral defects is a promising alternative to existing therapeutic options.

Initially, biodegradable materials were used in the authors' institute to fill mosaicplasty donor tunnels. Excessive postoperative bleeding from the donor site is a potential complication following mosaicplasty. In preclinical experimental studies, different biodegradable materials were studied for donor site filling to prevent excessive postoperative bleeding and the quality of repair tissue formation on the surfaces of these plugs were examined. ${ }^{[15]}$ The cylindrical plugs were made of hydroxyapatite, carbon fiber, polyglyconate-B, compressed collagen and polycaprolactones, and were implanted into donor tunnels created in the knees of 50 German Shepherd dogs. All materials effectively decreased postoperative bleeding and arthroscopic and histological evaluations showed a good integration to the surrounding bone, but a limited repair tissue formation with hydroxyapatite, polyglyconate-B, melted polycaprolactone and carbon rods. Only compressed collagen served as an appropriate scaffold for the formation of fibrocartilage coverage on the articular surface, and the plug was gradually substituted by bone formation.

Biodegradable scaffolds were also implanted into human mosaicplasty donor tunnels to prevent possible postoperative bleeding. Porous poly(ethylene oxide-terephthalate)/poly(butylene terephthalate) (PEOT/PBT) implants were used for donor site filling and macroscopic and histological analysis and magnetic resonance imaging (MRI) evaluation were carried out at nine months. ${ }^{[16]}$ The PEOT/PBT implants prevented postoperative bleeding in all cases, supported subchondral cancellous bone formation and congruent resurfacing with mainly fibrocartilaginous tissues.

Furthermore, biodegradable, off-the-shelf cylindrical osteochondral scaffolds can be used for the treatment of focal chondral and osteochondral defects, since they are intended to serve as a scaffold for cellular and tissue ingrowth in defect repair. They are designed to imitate the composition of human bone and cartilage and allow both bone and cartilage to regenerate. Following insertion procedure, the implants become impregnated with blood from the bone marrow cavity containing stem cells which carry out cartilage and bone repair, while the implant gradually resorbs. The implantation technique is similar to the one described for mosaicplasty, but without the need to harvest osteochondral plugs, which is a great advantage of the technique over osteochondral autograft transplantation, as donor site morbidity can be likely avoided. The implant is secured with a press-fit technique into the defect and becomes saturated with bone marrow cells and blood, when the intra-articular fluid pressure is reduced.

ChondroMimetic, a biodegradable cylindrical osteochondral CE marked scaffold was implanted in 17 patients in the authors' institute. In 15 cases, it was used to fill mosaicplasty donor sites, with mosaicplasty being performed in the knee $(n=12)$ or ankle $(n=3)$, whereas in two cases it served to treat
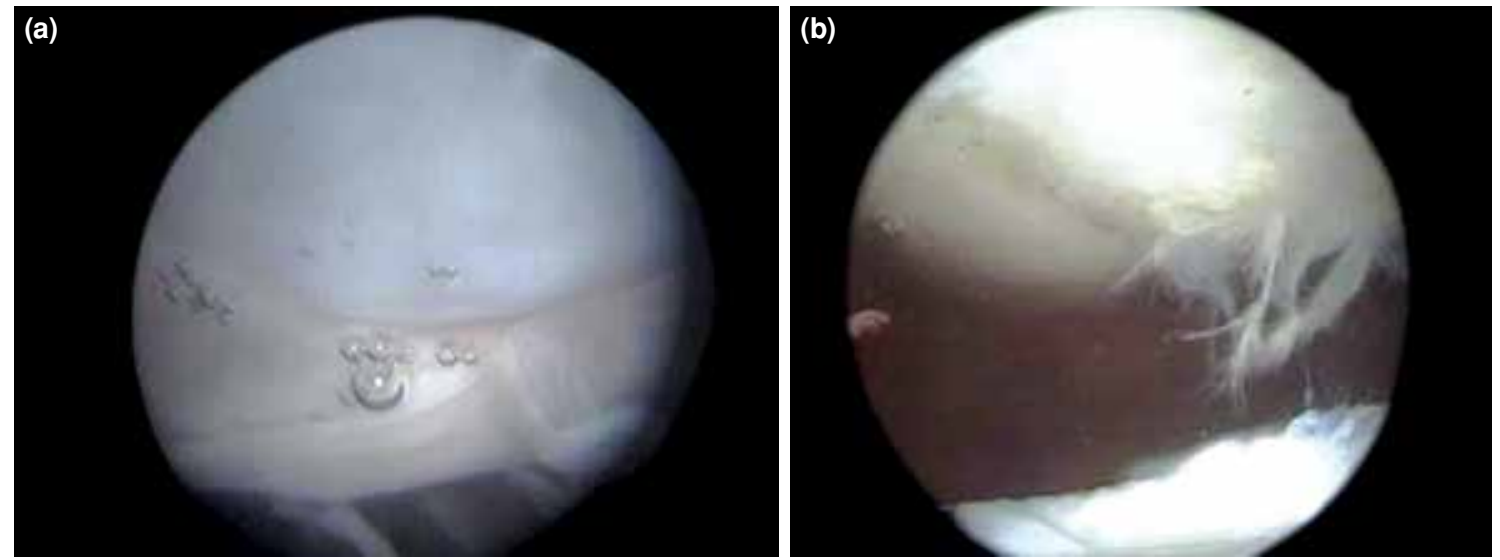

Figure 2. Second-look arthroscopies performed one year after matrix induced autologous chondrocyte implantation, the reparative tissue is softer, (a) than normal hyaline cartilage and (b) fibrillation of the surface can be observed. 
primary osteochondral defects of the medial femoral condyle. Early clinical results have been favorable, demonstrating a good safety profile of the implant. Histological examination showed the presence of a durable fibrocartilage surface with characteristics of hyaline cartilage; however, the structure of the reparative tissue was not identical with the structure of normal hyaline cartilage (unpublished results, publication submitted).

\section{Therapeutic algorithms and indications}

Herein, the question arises as to what the indications are of the cartilage repair techniques described above. Emphasis should be on analyzing the exact pathogenesis of cartilage damage in the selection of a therapeutic approach. For generalized lesions (i.e. immunological and rheumatologic disorders, inflammations, metabolic diseases), surgical resolution of extensive destructions in the late period are normally limited to total joint replacements. The indications for cartilage repair include injuries due to biomechanical factors or direct traumas, and aseptic bone necrosis caused by circulatory disturbance. The size, location and containment of the lesion determine the therapeutic approach, as well as previous surgical interventions on the affected joint.

Moreover, proper patient selection is crucial for a predictable and favorable outcome of the treatment. Decision on surgical management of cartilage lesions depends on the patient's age, physical fitness and activity, comorbidities and associated injuries. Postoperative weight-bearing restrictions require a compliant patient with a potential for completion of the postoperative rehabilitation and with realistic expectations regarding the outcome of the surgery.

Arthroscopic evaluation provides the most reliable information on location, depth and size of the lesion and status of the surrounding cartilage and the opposing chondral surface and helps to determine the suitability of the distinct cartilage repair techniques.

In addition, approaches which offer hyaline cartilage coverage or a surface which approximates the hyaline cartilage in quality - for reparation of cartilage defects are definitely superior to connective tissue or fibrocartilage surfaces. Accordingly, it is mandatory to strive for the use of modern cartilage repair techniques.

\section{Microfracture}

Microfracture is a widely used and favored technique for the treatment of cartilage defects, as it can be performed arthroscopically and does not require a great experience on behalf of the surgeon without a need for expensive materials. The most common indication is well-contained, monopolar lesions up to $4 \mathrm{~cm}^{2}$, although the indication can be extended to larger and bipolar lesions. Clinical success of microfracture is age-dependent, whereas the best clinical outcome can be expected in younger and active patients ( $<40$ years).

Microfracture is a first-line treatment for lesions up to $4 \mathrm{~cm}^{2}$ and it offers a great advantage as it does not burn bridges. In the presence of satisfactory clinical outcomes, a prior microfracture does not interfere with further surgical treatment of the same lesion. Furthermore, microfracture is the only cartilage repair technique, which can be attempted in the presence of degenerative changes and advanced arthrosis.

Indications of autologous matrix induced chondrogenesis correspond with the indications of microfracture, although microfracture still remains the first choice for treatment for lesions less than $2.5 \mathrm{~cm}^{2}$.

\section{Mosaicplasty}

Mosaicplasty is mainly recommended for the treatment of focal, 1-4 $\mathrm{cm}^{2}$-sized chondral and osteochondral defects of the femoral condyles and the patellofemoral joint; however, the indication can be extended to articular surfaces of the tibia and talus. Donor-site availability determines the optimal extent of defect coverage; in general patellofemoral peripheries allow graft harvest for 3-4 $\mathrm{cm}^{2}$-sized defects.

Although the notch area may serve as an additional donor site due to its concave cartilage surface and the stiffer underlying bone, grafts harvested from there have less favorable characteristics. Utilization of all possible donor sites would allow the treatment of defects up to $6-8 \mathrm{~cm}^{2}$ in size by mosaicplasty; however, such an extensive graft harvest can lead to increased risk of donor-site morbidity.

Absolute contraindications for mosaicplasty include conditions such as generalized or rheumatoid arthritis and lesions caused by infection or tumors, as pathobiochemical changes on the recipient site interfere with survival of the transplanted graft. Further absolute contraindications are defects larger than $8 \mathrm{~cm}^{2}$ in diameter and deeper than $10 \mathrm{~mm}$, lack of appropriate donor area and patients over 50 years of 
age due to their decreased repair capacity. Relative contraindication can be defects between 4 and 8 $\mathrm{cm}^{2}$ in diameter, mild osteoarthritic changes and patients aged between 40 and 50 years.

\section{Osteochondral allograft transplantation}

Fresh osteochondral allografts transplantation is usually recommended in case of severe, massive bone defects, as the sole option to avoid or postpone total joint replacement. Disadvantages of the procedure include the extremely long rehabilitation period (can be as long as 1 year), potential risk of virus transmission, donor availability, and also, the technique requires substantial experiences on behalf of the surgeon. Furthermore, direct, local graft harvest for implantation within 12-24 hours requires well organized and efficient logistics which may not be available in many institutes.

\section{Autologous chondrocyte implantation}

Autologous chondrocyte implantation can be considered as the first-line treatment for symptomatic, full thickness chondral or osteochondral defects larger than $2 \mathrm{~cm}^{2}$ and as the second-line treatment for defects less than $2 \mathrm{~cm}^{2}$, when bone marrow stimulation techniques have failed. Ideally, the lesions should be surrounded by healthy cartilages; however, uncontained lesions are not an absolute contraindication for ACI. The most optimal results can be achieved, if ACI is used for the treatment of superficial osteochondral lesions.

Contraindications for ACI, similar to mosaicplasty, include severe osteoarthritis, bipolar lesions, active rheumatoid arthritis or autoimmune connective tissue diseases, and malignant tumors.

\section{Biodegradable osteochondral scaffolds}

Cylindrical osteochondral scaffolds are intended for patients who are suffering from small-sized (up to 1.0-1.5 $\mathrm{cm}^{2}$ ) primary chondral/osteochondral defects caused by sports injuries, trauma and early stage osteoarthritis, and also for the treatment of secondary, surgically prepared osteochondral graft sites.

The implants are available in different sizes, determining the extent of the lesions that can be treated with them, which should be based on the manufacturers' recommendations.

Within this context, several factors should be taken into account during the composition of a rehabilitation program to contribute to the achievement of movement and motion. The main elements of rehabilitation following cartilage repair techniques are ensuring appropriate motion of the joint and gradually increased loading of the treated surfaces.

It has been shown that immobilization can lead to inadequate nutrition of the cartilage, ${ }^{[17]}$ therefore, the initial principle of rehabilitation is to avoid any kind of immobilization of the joint. Immediate ROM should be encouraged following all cartilage repair procedures: it enhances nutrition of the cartilage and circulation, promotes development of congruent surfaces, and prevents contractures and adhesions in the joint. Since active ROM exercises, cyclic closed chain exercises, in particular, have better nutritional effects than passive motion active exercising should be started as tolerated from the first postoperative day. Limited ROM may become necessary following treatment of patellofemoral defects and certain concomitant procedures. Open procedures, causing more pain, swelling and extended soft tissue involvement may hinder ROM.

Loading should be increased gradually; the level of loading is based on the type of cartilage repair technique and extent of the defect. Step-by-step increase of loading and difficulty of exercises is essential- in particular in case of larger defects. Shear forces represent extraloading for the treated surface for uncontained lesions, particularly.

Muscle strengthening exercises are comprised of open chain exercises and isometric exercises in the non-weight-bearing period, whereas resistance and loading of muscles are increased gradually. In the partial weight-bearing period, closed chain exercises are added, and as full weight-bearing is allowed, proprioceptive training can also be started. Welladapted proprioceptive exercises can also help to avoid extreme injury conditions.

The following recommendations for rehabilitation are based on the current rehabilitation protocols in the authors' institution.

\section{Microfracture}

Besides achieving satisfactory movement and motion, rehabilitation following microfracture also contributes to the formation of a durable fibrocartilage layer over the defect area. Range of motion exercises may promote a better contouring and better quality of the treated surface, as motion helps formation of fibrocartilage. Passive and active motion is beneficial for cartilage nutrition and enhances circulation, which lessens swelling of the treated joint. Also, proper circulation is essential to ensure bleeding of the treated surface for appropriate cell invasion. 
Furthermore, continuous passive motion (CPM) plays an important role in the early phase of rehabilitation and it is recommended for at least 3-4 hours/day in the first 2 to 5 days, depending on the size of the defect. Steadman et al. ${ }^{[1]}$ recommend the use of CPM for a longer period, for several weeks, as it supports fibrocartilage formation in the defect.

Initially, the soft regenerative tissue should be protected from loading, and weight-bearing should not be allowed in the first couple of weeks. Following the initial phase, a well-adapted loading protocol is applied for the construction of a proper collagen structure in the repair tissue, as the stimulus for fibrocartilage formation of connective tissue is loaded. Loading should be increased gradually: the surface needs loading, however, the newly forming tissue should not be overloaded. In this phase of rehabilitation, the focus should be on closed chain exercises and motivation of the patients to walk with partial weight-bearing for longer periods.

Full weight-bearing can be achieved by the fourth, sixth or eighth week, depending on the size and location of the defect. As running represents an extra loading, it should be started after 10 to 12 weeks following surgery. Directional changes can be allowed after three to five months, and sports activity at four to six months postoperatively.

Sequence of loading following microfracture:

- Non-weight-bearing: 2 to 4 weeks (CPM!)

- Partial weight-bearing: Additional 2 to 3 (-4) weeks

- Full weight-bearing: 4 to 8 postoperative weeks

- Running (straight-line): 10-12 postoperative weeks

- Directional changing: 3 to 5 postoperative months

- Sports activity:

4 to 6 postoperative months

\section{Mosaicplasty}

Following mosaicplasty, fibrocartilage ingrowth is expected between the grafts. The final goal is to develop a composite cartilage layer consisting of transplanted hyaline cartilage and fibrocartilage. The ROM exercises facilitate healing and contouring of the reparative tissue forming in the 'dead spaces' between the cylindrical grafts and also contouring possible incongruences of the resurfaced area. Additionally, enhancement of subchondral circulation may promote bone healing between the bony part of the grafts and the surrounding host area.

Preclinical animal studies suggested that unprotected weight-bearing might have a detrimental influence on integration of the bone segment of the transplanted osteochondral graft. ${ }^{[18]}$
Graft subsidence, necrosis of the subchondral bone and overgrowth with fibrous or fibrocartilagenous tissue were observed in over one-third of the weightbearing cases. Based on these result, at an early stage of mosaicplasty, a longer period of postoperative non-weight-bearing was recommended in human practice. Later, it was observed, during second-look arthroscopies, that extended non-weight-bearing did not favor tissue regeneration between grafts. A certain level of loading is necessary for fibrous cartilage formation in the interposed tissue (instead of fibrous repair tissue), leading to shortened sequence of nonweight-bearing and prolonged sequence of partial weight-bearing period during rehabilitation. ${ }^{[19,20]}$

Diameter and number of grafts also play a role in the identification of the length of non-weight-bearing period. It was shown that larger grafts are more stable in absolute values, and multiple grafts may not be as stable as single grafts in the initial period following transplantation. ${ }^{[21]}$ Therefore, restriction of weight-bearing is recommended for a certain period of time following mosaicplasty to avoid graft subsidence, until bony integration occurs.

Rehabilitation protocol can be also modified according to the location, type, and size of the defect and to the surgical approach applied. For instance, arthroscopic cases may need a shorter rehabilitation period with regard to loading, ROM, and proprioception return. On contrast, larger, osteochondral defects, and uncontained lesions require longer non-weight-bearing than arthroscopic procedures. In the presence of smaller defects, the period of rehabilitation can be shorter and shear forces and sports activities can be allowed earlier.

The present recommendations for rehabilitation following mosaicplasty in our institute are as follows:[22]

The cornerstone of rehabilitation is to ensure early motion of the treated joint to promote appropriate nutrition of the transplanted cartilage; early ROM is encouraged, and immobilization should be avoided. If concomitant procedures require external fixation of the operated joint (e.g. meniscus reinsertion), ROM can be limited by bracing for a short time period.

Partial loading promotes transformation of connective tissue (between transplanted plugs) into fibrocartilage, which makes closed chain exercises essential during the course of rehabilitation in the half weight-bearing period, in particular. Also, some of the closed-chain exercises (e.g. cycling) ensure cyclic loading, making fluid- and nutrition-transport 
Ambulation

- Two-crutch ambulation, non-weight-bearing

- Two-crutch ambulation, partial loading (30 to $40 \mathrm{~kg}$ )

- Discontinue crutches, full weight-bearing

Functional exercises

- Form walking, gait evaluation

- Step-up

- Step-down

Range of motion

- $\mathrm{CPM}$ for 2 to $4 \mathrm{~cm}^{2}$ lesions (in painless range)

- Full extension, flexion as tolerated

- Stationary bicycle

Muscle strength exercises should be started as follows:

Quadriceps

- Open chain exercises, leg raises

- Concentric contraction to full extension

- Concentric contraction against resistance

- Isometric exercises in different angles

- Eccentric exercises against resistance

Hamstrings

- Isometric exercises in different angles

- Concentric and eccentric strengthening against resistance
Immediate

2 to 4 weeks

3 to 5 weeks

3 to 5 weeks

4 to 5 weeks

5 to 6 weeks

Immediate ( 2 to 4 hours/day in the $1^{\text {st }}-3^{\text {rd }}$ postoperative days) Immediate

3 to 4 weeks (if $90^{\circ}$ knee flexion has been achieved)

\author{
Immediate \\ 1 week (or earlier if tolerated) \\ 2 weeks \\ Immediate \\ 3 to 4 weeks
}

Immediate

1 to 2 weeks

3 to 4 weeks substantially more efficient between synovial fluid and hyaline cartilage.

\section{Closed chain exercises}

- Pushing a soft rubber-ball with foot Immediate

- Closed chain exercises with half weight-bearing

2 to 3 weeks with full weight-bearing

- Stationary bicycle with resistance

- Stairmaster

5 to 6 weeks

2 to 4 weeks

6 to 8 weeks

Proprioceptive training

- Balance exercises standing on both feet

- Standing on one foot - hard ground

5 to 6 weeks

6 to 8 weeks

- Standing on one foot - trampoline or aerostep

8 to 10 weeks

The final goal of rehabilitation is to facilitate the patients' return to daily and sports activities. It must be noted that it takes approximately four to five months to form a composite hyaline-like surface over the transplanted area, which is able to tolerate shear forces. Returning to sports activities depends on the depth and extent of the defect as well as the state of the neuromuscular system. If the patients' strength, power, endurance, balance and flexibility are not satisfactory, sports activity should

be delayed. General recommendations for return to sports activity are as follows:

- Jogging

- Straight-line running

- Directional changes

- Sport specific adaptations

- Shear forces

- Sports activity

The size, location and type (chondral or osteochondral) of the defect can also modify weightbearing restrictions. If the defect is chondral, located on the femoral or tibial condyle and less than $15 \mathrm{~mm}$ in diameter:

- Non-weight-bearing

1 week

- Partial weight-bearing

1 to 3 weeks

If the defect is chondral, located on the femoral or tibial condyle and larger than $15 \mathrm{~mm}$ in diameter:

- Non-weight-bearing 2 weeks

- Partial weight-bearing

2 to 4 weeks

If the defect is osteochondral and located on the femoral or tibial condyle:

- Non-weight-bearing 3 weeks

- Partial weight-bearing 
If the defect is located on the patella and less than $15 \mathrm{~mm}$ in diameter, immediate partial weight-bearing is recommended for two weeks, for lesions larger, than $15 \mathrm{~mm}$ in diameter, the period of partial weightbearing should be three weeks.

Quadriceps strengthening exercises and patellar mobilization differ following treatment of patellar defects, the emphasis should be on vastus medialis strengthening:

- Isometric exercises in extension Immediate

- Patellar mobilization Immediate

- Closed chain exercises 1 week

- Isometric exercises in different angles 1 week

- Open chain exercises against resistance 2 weeks 3 to 4 weeks

- Eccentric exercises against resistance

4 to 5 weeks

Mosaicplasty is combined with a concomitant procedure aiming to reconstruct biomechanical alterations in about $80 \%$ of the cases in our practice. The treatment of accompanying pathologies requires a special adaptation of the rehabilitation protocol in most cases. The most frequent combinations at knee applications are as follows:

ACL-reconstruction combined with mosaicplasty:

- 3 to 4 weeks non-weight-bearing (due to mosaicplasty)

- Additional 1 to 2 weeks partial weight-bearing

- $0-90^{\circ} \mathrm{ROM}$ for 3 weeks

- Mainly closed chain exercises for quadriceps strengthening

- Hamstring strengthening in open and closed chain

- Proprioceptive training

- Straight-line running: 10 to 12 weeks

- Directional changes: 12 to 14 weeks

- Sports activities: 4 to 5 months

Meniscus reinsertion combined with mosaicplasty:

- 3 to 4 weeks non-weight-bearing

- Additional 1 week partial weight-bearing

- 5-45 ROM for 4 weeks

- Straight-line running: 12 weeks

- Directional changes: 14 weeks

- Sports activities: 4 to 5 months

Retinaculum patellae reconstruction combined with mosaicplasty:

- 2 to 4 weeks non-weight-bearing (due to mosaicplasty)
- One more week partial weight-bearing

- $0-45^{\circ} \mathrm{ROM}$ for 4 weeks

- Straight-line running: 12 to 14 weeks

- Directional changes: 14 to 16 weeks

- Sports activities: 5 months

HTO combined with mosaicplasty:

Closed wedge HTO:

- Sequence of weight-bearing is determined by mosaicplasty, but for four weeks weight-bearing is allowed only in extension

- Returning to higher activity levels is determined by mosaicplasty and neuromuscular status of the patient

Open wedge HTO:

- Three weeks non-weight-bearing

- Additional three weeks partial weight-bearing

- Returning to higher activity levels is determined by mosaicplasty and neuromuscular status of the patient

Rehabilitation following implantation of cylindrical osteochondral scaffolds corresponds with the rehabilitation protocol of mosaicplasty, unless otherwise instructed by the manufacturer of the graft.

\section{Autologous chondrocyte implantation}

Postoperative motion (mainly passive motion) following autologous chondrocyte implantation helps further differentiation and good ingrowth between newly formed bone and cartilage: oxygenation helps bone and motion helps cartilage formation.

After chondrocyte implantation ROM should be increased gradually to protect the resurfaced area from extra pressure.

In case of femoral defects:

- 0-60 for two weeks

- $0-90^{\circ}$ between $3^{\text {rd }}$ and $6^{\text {th }}$ postoperative weeks

- Full ROM at 7 weeks

and patellar defects:

- $0-45^{\circ}$ for four weeks

- $0-60^{\circ}$ between $5^{\text {th }}$ and $6^{\text {th }}$ postoperative weeks

- $0-90^{\circ}$ between $7^{\text {th }}$ and $8^{\text {th }}$ postoperative weeks

- Full ROM at 9 weeks

Forced active exercising can apply too much pressure onto the resurfaced area, and 4 to 5 hours of CPM is suggested in the first one or two postoperative weeks. In our practice, a relatively 
short non-weight-bearing period is followed by a longer partial weight-bearing period, full weightbearing can be allowed after three months.

Sequence of loading following autologous chondrocyte implantation:

- Non-weight-bearing

4 weeks (CPM!)

- Partial weight-bearing

additional 8(!) weeks

- Full weight-bearing after 12 postoperative weeks

- Running (straight-line) after 4 to 5 postoperative months

- Directional changing

after 6 to 7 postoperative months

- Sports activity

after 7 to 8 postoperative months

\section{Osteochondral allograft transplantation}

Structural allograft transplantation requires specifically composed rehabilitation protocol, the periods of non-weight-bearing, partial weightbearing and full weight-bearing depend on the rate of graft incorporation, which is detected by radiographic imaging techniques. Moreover, graft size and stability at the time of procedure are important, and fixation technique of the graft must also be considered.

Such a individually tailored rehabilitation program is presented in the following section in a case study of a 29-year-old male patient who suffered from Hoffa fracture of the lateral femoral condyle due to a car accident. Following internal fixation of the fracture with screws, the patient developed a septic complication. Subsequently, the internal fixation was removed, the septic complication was eliminated, and as a consequence, the patient developed a massive osteochondral defect of the lateral femoral condyle (Figure 1). The ROM was $0-115^{\circ}$ degrees with serious multidirectional and moderate sagittal instability. The patient had difficulty in weight-bearing, was able to mobilize only in brace, and was scheduled for osteochondral allograft transplantation.

The rehabilitation after transplantation started within three months of non-weight-bearing period and the patient was allowed to mobilize in brace. The allowed $\mathrm{ROM}$ was $0-30^{\circ}$ during the first four weeks, $0-45^{\circ}$ between four and eight weeks, and $060^{\circ}$ between eight and 12 weeks. At the third postoperative month, the patient underwent outpatient physiotherapy and the allowed ROM range of motion was $0-90^{\circ}$ for two weeks, and, unlimited afterwards. Weight-bearing was restricted to $20 \mathrm{~kg}$ for one month, and, then, the patient was able to start full weight-bearing in extension. At four months after surgery, loading was gradually increased and the patient was allowed to mobilize without crutches. Partial weight-bearing was started in flexion as well, along with proprioceptive training.

In summary:

weight-bearing restrictions:

- Non-weight-bearing 3 months

- Partial weight-bearing $(20 \mathrm{~kg}) \quad 1$ month

- Full weight-bearing in extension At three months

- Full weight-bearing in extension At four months

Range of motion:

- $0-30^{\circ}$ in the first 4 weeks

- $0-45^{\circ}$ between weeks 4 and 8

- $0-60^{\circ}$ between weeks 8 and 12

- 0-90 between weeks 12 and 14

- Unlimited after week 14

The patient was followed closely by radiological imaging, physical examination, scintigraphy and had a control arthroscopy at the time of removal of internal fixation. Decision on the progress of rehabilitation was made based on clinical finding. Of note, the patient's compliance and strict adherence to the prescribed protocol was critical for the success of rehabilitation.

\section{Conclusion}

Cartilage repair procedures intend to restore the articular surface over chondral and osteochondral lesions. Success of the treatment is based on three factors: choosing the adequate cartilage repair technique, correction of any accompanying joint abnormalities and application of a well-composed rehabilitation protocol. The decision of choosing cartilage repair techniques should be based on careful consideration of indications and contraindications of the procedures, type, size and location of the lesions, medical history of the patients and their expectations of the outcome of surgery. Excluding correction of accompanying pathologies of the joint can lead to early wear of the resurfaced area and even to further deterioration of the condition. Postoperative rehabilitation protocol should start with immediate ROM exercises, as it promotes nutrition of the resurfaced area. Restrictions of weight-bearing and progress of rehabilitation should be adapted according to the type of cartilage repair technique, concomitant procedures and activity prior to injury. 


\section{Declaration of conflicting interests}

The authors declared no conflicts of interest with respect to the authorship and/or publication of this article.

\section{Funding}

The authors received no financial support for the research and/or authorship of this article.

\section{REFERENCES}

1. Steadman JR, Rodkey WG, Rodrigo JJ. Microfracture: surgical technique and rehabilitation to treat chondral defects. Clin Orthop Relat Res 2001;391:362-9.

2. Schindler OS. Current concepts of articular cartilage repair. Acta Orthop Belg 2011;77:709-26.

3. Hangody L, Dobos J, Baló E, Pánics G, Hangody LR, Berkes I. Clinical experiences with autologous osteochondral mosaicplasty in an athletic population: a 17-year prospective multicenter study. Am J Sports Med 2010;38:1125-33.

4. Lexer E. Substitution of whole or half joints from freshly amputated extremities by free plastic operation. Surg Gynaecol Obstet 1908;6:601-7.

5. Convery FR, Akeson WH, Keown GH. The repair of large osteochondral defects. An experimental study in horses. Clin Orthop Relat Res 1972;82:253-62.

6. Mankin HJ, Doppelt S, Tomford W. Clinical experience with allograft implantation. The first ten years. Clin Orthop Relat Res 1983;174:69-86.

7. Pritzker KP, Gross AE, Langer F, Luk SC, Houpt JB. Articular cartilage transplantation. Hum Pathol 1977;8:635-51.

8. Csönge L, Bravo D, Newman-Gage H, Rigley T, Conrad EU, Bakay A, et al. Banking of osteochondral allografts, Part II. Preservation of Chondrocyte Viability During Long-Term Storage. Cell Tissue Bank 2002;3:161-8.

9. Williams SK, Amiel D, Ball ST, Allen RT, Wong VW, Chen AC, et al. Prolonged storage effects on the articular cartilage of fresh human osteochondral allografts. J Bone Joint Surg [Am] 2003;85:2111-20.

10. Hangody LR, Gál T, Szúcs A, Vásárhelyi G, Tóth F, Módis L, et al. Osteochondral allograft transplantation from a living donor. Arthroscopy 2012;28:1180-3.

11. Brittberg M, Lindahl A, Nilsson A, Ohlsson C, Isaksson $\mathrm{O}$, Peterson L. Treatment of deep cartilage defects in the knee with autologous chondrocyte transplantation. N Engl J Med 1994;331:889-95.

12. Peterson L, Vasiliadis HS, Brittberg M, Lindahl A. Autologous chondrocyte implantation: a long-term followup. Am J Sports Med 2010;38:1117-24.

13. Bartlett W, Skinner JA, Gooding CR, Carrington RW, Flanagan AM, Briggs TW, et al. Autologous chondrocyte implantation versus matrix-induced autologous chondrocyte implantation for osteochondral defects of the knee: a prospective, randomised study. J Bone Joint Surg [Br] 2005;87:640-5.

14. Gooding CR, Bartlett W, Bentley G, Skinner JA, Carrington $R$, Flanagan A. A prospective, randomised study comparing two techniques of autologous chondrocyte implantation for osteochondral defects in the knee: Periosteum covered versus type I/III collagen covered. Knee 2006;13:203-10.

15. Feczkó P, Hangody L, Varga J, Bartha L, Diószegi Z, Bodó $\mathrm{G}$, et al. Experimental results of donor site filling for autologous osteochondral mosaicplasty. Arthroscopy 2003;19:755-61.

16. Bartha L, Hamann D, Pieper J, Péters F, Riesle J, Vajda A, et al. A clinical feasibility study to evaluate the safety and efficacy of PEOT/PBT implants for human donor site filling during mosaicplasty. Eur J Orthop Surg Traumatol 2013;23:81-91.

17. O'Hara BP, Urban JP, Maroudas A. Influence of cyclic loading on the nutrition of articular cartilage. Ann Rheum Dis 1990;49:536-9.

18. Menke W, Schmitz B. Large autogenous osteochondral graft for replacing knee cartilage defect. Orthopedics 1999;22:631-2.

19. Bartha L, Vajda A, Duska Z, Rahmeh H, Hangody L. Autologous osteochondral mosaicplasty grafting. J Orthop Sports Phys Ther 2006;36:739-50.

20. Hangody L, Feczkó P, Kemény D, Bodó G, Kish G. Autologous osteo-chondral mosaicplasty for the treatment of full thickness cartilage defects of the knee and ankle. Clin Orthop Relat Res 2001;391:328-37.

21. Kordás G, Szabó JS, Hangody L. Primary stability of osteochondral grafts used in mosaicplasty. Arthroscopy 2006;22:414-21.

22. Hangody L, Duska Zs, Kárpáti Z. Osteochondral plug transplantation. In: Jackson $D$, editor. Mastertechniques in Orthopaedics; The Knee. 2nd ed. New York: LippincottWilliams-Wilkins; 2007. p. 395-409. 